\title{
Ophthalmic Strip Dosage Form
}

National Cancer Institute

\section{Source}

National Cancer Institute. Ophthalmic Strip Dosage Form. NCI Thesaurus. Code C149705.

Solid sterile single-dose preparation consisting of a strip made of a suitable material usually impregnated with active substance(s) intended for use on the eyeball. 